\title{
SUSTRACCIÓN INTERNACIONAL DE MENORES Y ENFERMEDAD PSIQUIÁTRICA DEL PROGENITOR NO SUSTRACTOR. COMENTARIO DEL AUTO DE LA AUDIENCIA PROVINCIAL DE LES ILLES BALEARS (SECCIÓN IV), NÚM. 37/2018, DE 14 DE JUNIO
}

\author{
INTERNATIONAL CHILD ABDUCTION AND PSYCHIATRIC \\ ILLNESS OF THE NON-ABDUCTING PARENT. COMMENT ON \\ THE JUDGMENT OF THE SPANISH COURT OF APPEAL OF LES \\ ILLES BALEARS (SECTION IV) NUMBER 37/2018 OF $14^{\text {th }}$ JUNE
}

\author{
Marí́A GonZÁlez MarimóN* \\ Investigadora FPU de Derecho internacional privado \\ Universitat de València
}

Recibido: 15.01.2019 / Aceptado: 22.01.2019

DOI: https://doi.org/10.20318/cdt.2019.4648

\begin{abstract}
Resumen: Sustracción ilícita internacional a España de dos menores residentes en Reino Unido en aplicación del Reglamento Bruselas II bis y el Convenio de La Haya de 1980 sobre los aspectos civiles de la sustracción internacional de menores. Discusión sobre si la enfermedad psiquiátrica de la madre constituye un riesgo de peligro físico o psíquico en caso de retorno de los menores, en los términos de la excepción al retorno del artículo 13 b del Convenio de La Haya de 1980.

Palabras clave: sustracción internacional de menores, Reglamento Bruselas II bis, Convenio de La Haya de 1980, excepciones al retorno del menor, excepción del artículo 13 b.

Abstract: International child abduction to Spain of two minors residing in United Kingdom under the Brussels II Regulation and the Hague Convention on the Civil Aspects of International Child Abduction of 1980. Discussion about if the psychiatric illness of the mother is considered as a risk of physical or psychological harm in case of return of the minors, in terms of the article $13 \mathrm{~b}$ return exception of the 1980 Hague Convention.

Keywords: international child abduction, Brussels II bis Regulation, 1980 Hague Convention, exceptions to the return of the minor, article $13 \mathrm{~b}$ exception.

Sumario: I. Introducción. II. Hechos. III. Consideraciones jurídicas. 1. Cuestiones formales relativas a las normas procesales internas sobre sustracción internacional de menores. 2. La ilicitud del traslado de los menores, 3. El consentimiento de la madre como excepción al retorno. 4. La enfermedad psiquiátrica de la madre como excepción al retorno por grave riesgo de los menores. IV. Valoración final.
\end{abstract}

*Ayuda para la Formación del Personal Universitario, financiaciada por el Ministerio de Ciencia, Innovación y Universidades. 


\section{Introducción}

1. El 14 de marzo de 2018 la Audiencia Provincial de Les Illes Balears, Sección IV, estimó un recurso de apelación en un procedimiento sobre sustracción internacional de menores ordenando la restitución de dos menores de España a Reino Unido, país en el que tenían su residencia habitual con carácter previo al traslado ilícito.

2. En el presente comentario en primer lugar se expondrán los hechos (II), para a continuación abordar las consideraciones jurídicas de interés (III), las cuales son: 1. Cuestiones formales relativas a las normas procesales internas sobre sustracción internacional de menores, 2. La ilicitud del traslado de los menores, 3. El consentimiento de la madre como excepción al retorno, 4. La enfermedad psiquiátrica de la madre como excepción al retorno por grave riesgo de los menores, concluyendo con una valoración final (IV).

\section{Hechos}

3. Con carácter previo a la descripción de los hechos se debe advertir que el auto analizado no contiene una descripción fáctica detallada y ordenada, sino que entra a resolver directamente los problemas jurídicos planteados en el supuesto. Remitiéndose a lo largo del auto, cuando es necesario para la argumentación, a hechos concretos.

4. Teniendo esto en cuenta, los hechos pueden resumirse como sigue: el litigio enfrenta a dos progenitores, de los que se desconoce su nacionalidad, siendo la residencia habitual de la madre Reino Unido y la del padre desconocida, respecto a la sustracción por parte del padre de sus dos hijos de Reino Unido a España (Mallorca) el 2 de septiembre de 2017. Nos encontramos pues ante un supuesto típico de sustracción internacional de menores, en el que no se aclara si la custodia es compartida o exclusiva en favor de uno de los progenitores.

5. El elemento fáctico más singular que presenta el caso es la enfermedad psiquiátrica que padece la madre. De hecho, en la fecha en la que el padre traslada a los menores, la madre se encuentra hospitalizada ${ }^{1}$. Otra información relevante es que durante el tiempo que transcurre hasta la finalización del procedimiento, los menores son escolarizados en Mallorca. Además, la madre acude a visitarles en dicho periodo, llegando a firmar incluso la solicitud de escolarización de los niños.

6. Finalmente, es de relevancia destacar que la madre presenta una demanda por el traslado ilícito de los menores cuando aún no ha transcurrido un año desde la fecha del traslado de éstos de Reino Unido a España.

7. El 15 de enero de 2018 el Juzgado de Primera Instancia $n^{\circ} 16$ de Palma de Mallorca dictó auto por el cual desestimó la pretensión de retorno de dos menores a Reino Unido, con su madre. El conjunto de factores por los que el Juzgado deniega la restitución, citando a la Audiencia Provincial, son los siguientes: "la enfermedad psiquiátrica de la madre que, aun estabilizada en el momento de dictar su resolución y dada la evolución de su dolencia, le lleva a temer que vuelva a intensificarse; el consen-

\footnotetext{
${ }^{1}$ Del informe médico-forense de 11 de enero de 2018, citado en el auto, se extrae que el estado actual de la madre es el que sigue: que a la madre se le diagnosticó trastorno afectivo bipolar, seguido y tratado durante cuatro años. Tras diez años desde el diagnóstico y por causa del estrés durante los estudios universitarios, recayó en un nuevo ingreso y desde entonces aparentemente no ha cesado la medicación y el tratamiento. Actualmente, "sigue un tratamiento pautado por su médico de cabecera, psiquiatra y por el servicio de atención psiquiátrica, viviendo actualmente sola y aunque no tiene familia, recibe la ayuda de un grupo de amigas y de una hermana de su ex marido, percibiendo de éste una pensión de 3000 euros, desenvolviéndose bien en casa y no siéndole necesaria ayuda exterior alguna, participando en voluntariados de cocina y ejercitando caminatas, meditación y tareas de restauración, encontrándose, según ella, en estado eutímico y optimista".
} 
timiento de la madre para el traslado de sus hijos a Mallorca y su escolarización en el centro en el que se encuentran, así como la adaptación de los mismos a esa escuela y al propio entorno y el adecuado cuidado de los mismos que ejercen sus abuelos paternos con los que conviven; la ausencia de apoyo de la familia materna de la madre y la falta de adopción de medidas de protección de los menores por parte del Estado de origen en caso de restitución de los niños, considerando el juez de primera instancia que el retorno puede suponer a éstos peligros fisicos o psíquicos".

8. Disconformes con dicha decisión, tanto la madre de los menores, Doña Ofelia, como el Ministerio Fiscal interpusieron recurso de apelación ante la Audiencia Provincial de Les Illes Balears contra el auto mencionado, a los que se opuso el padre de los menores, Don Moisés. Frente a estos recursos, la Audiencia Provincial de les Illes Balears estima el recurso de apelación de Doña Ofelia y del Ministerio Fiscal, acordando la restitución inmediata de los menores a su país de origen, calificando por tanto el traslado de los menores a Mallorca como ilícito, y no apreciando la concurrencia de ninguna causa de excepción al retorno.

\section{Consideraciones jurídicas}

9. Una vez descritos los hechos y habiendo hecho referencia a la resolución dictada en primera instancia, es turno de exponer las cuestiones jurídicas más relevantes del supuesto de hecho particular, que son las siguientes.

\section{Cuestiones formales relativas a las normas procesales internas sobre sustracción internacional de menores}

10. La primera de las cuestiones jurídicas que aborda la Audiencia Provincial se refiere a un defecto formal en la aplicación de las normas procesales internas españolas relativas a la restitución o retorno de menores en supuestos de sustracción ilícita internacional. La legislación procesal española recoge un procedimiento específico en esta materia, fruto de una importante reforma llevada a cabo en $2015^{2}$. Concretamente, la Ley 15/2015, de 2 de julio, de la jurisdicción Voluntaria ${ }^{3}$ introdujo en la LEC del 2000, por primera vez en nuestro ordenamiento jurídico, un procedimiento autónomo sobre la restitución de menores. Este procedimiento está regulado en los nuevos artículos 778 quáter, quinquies y sexties de la LEC, pertenecientes al nuevo Capítulo IV bis relativo a "Medidas relativas a la restitución o retorno de menores en los supuestos de sustracción internacional"4.

\footnotetext{
${ }^{2}$ Esta reforma se enmarca en la reforma del sistema de protección del menor llevada a cabo por el legislador español en 2015. En este contexto, también destaca la Ley 26/2015, de 28 de julio, de modificación del sistema de protección a la infancia y a la adolescencia (BOE de 29 de julio de 2015) y la Ley 29/2015, de 30 de julio, de Cooperación Jurídica Internacional en materia civil (BOE de 29 de julio de 2015).

${ }^{3} B O E$ de 3 de julio de 2015.

${ }^{4}$ Sobre las reformas de la LEC en materia de sustracción internacional de menores véase: Circular 6/2015 de 7 de noviembre de 2015, de la FGE, sobre aspectos civiles de la sustracción internacional de menores; S. ADrohER Biosca: "Las reformas legales de 2015 ante los nuevos desafíos en la protección internacional de menores”, en M. GuZMÁn Zapater, y C. EsPLUGUeS Mota (dirs.): Persona y familia en el nuevo modelo español de Derecho Internacional privado, Tirant Lo Blanch, Valencia, 2017, pp. 333-350; S. CALAZA LóPEZ: Los procesos de restitución o retorno de menores en los supuestos de sustracción internacional, La Ley, Madrid, 2015; R. EsPinosa CALABUIG: "Traslado o retención ilícitos de menores tras la reforma de 2015: rapidez, especialización y... algunas ausencias”, Revista Española de Derecho Internacional, Sección Foro, vol. 68, n. ${ }^{\circ}$ 2, 2016; J. Forcada Miranda: "Complejidad, carencias y necesidades de la sustracción internacional de menores en el siglo XXI y un nuevo marco legal en España", Anuario Español de Derecho Internacional Privado, t. XVI, 2016, pp. 699-743; J. ForCADA MIRANDA: "El nuevo proceso español de restitución o retorno de menores en los supuestos de sustracción internacional: La decidida apuesta por la celeridad y la novedosa Circular de la Fiscalía 6/2015 (Partes I y II)", Bitácora Millennium DIPr., n. ${ }^{\circ} 3$, 2016. Versión on line disponible en www.milleniumdipr.com, último acceso el 12 de enero de 2019; J. Forcada MiRANDA: Sustracción internacional de menores y mediación familiar, Sepín, Madrid, 2015; C. MARÍN PedReÑo: Sustracción Internacional de Menores y proceso legal para la restitución del menor, Editorial Ley57, Málaga, 2016.
} 
11. En este marco, el Ministerio Fiscal detecta un defecto formal en la resolución recurrida, solicitando la nulidad de la misma por defecto de forma. Tal y como hemos mencionado, el Juzgado de Primera Instancia deniega el retorno de los menores mediante auto. Sin embargo, el Ministerio Fiscal argumenta que esta resolución es nula ya que debió tener forma de sentencia, de acuerdo con los previsto en los artículos 778 quater y siguientes de la Ley de Enjuiciamiento Civil. Efectivamente, el artículo 778 quinquies, relativo al procedimiento, en su apartado noveno, recoge que el Juez dictará sentencia en estos procedimientos 5 .

12. La Audiencia Provincial rechaza esta alegación argumentando que, si bien es correcta la afirmación del Ministerio Fiscal desde un estricto punto de vista formal, la resolución recurrida está debidamente motivada. A lo anterior el Tribunal añade que tampoco se han visto afectados otros aspectos relevantes como la tramitación procesal, el sistema de recursos ni la eventual ejecución de la resolución dictada. Es más, la propia Audiencia Provincial resuelve mediante auto el recurso ${ }^{6}$.

13. En definitiva, la Audiencia Provincial convalida el defecto de forma planteado por el Ministerio Fiscal, dándole prioridad al fondo de la cuestión. Quizá, un posible argumento para justificar la opción de la Audiencia Provincial sería el propio interés superior de los menores en que el asunto se resuelva en el menor plazo posible. El carácter urgente y preferente de los procedimientos de sustracción internacional de menores se deriva tanto del Convenio de La Haya de 1980 como del Reglamento Bruselas II bis, y ha sido asimismo recogido por la normativa procesal española tras las reformas de 2015 . Declarar la nulidad de la resolución, teniendo en cuenta que el defecto es meramente formal, hubiera ido en contra de este objetivo, retrasando innecesariamente el procedimiento, y alargando con ello la situación de inestabilidad e incertidumbre para los menores.

14. La Audiencia Provincial igualmente desestima una segunda cuestión formal relativa a una alegación por parte del Ministerio Fiscal de incongruencia omisiva por falta de pronunciamiento en la parte dispositiva del auto apelado sobre la ilicitud del traslado. Considerándolo una cuestión formal intrascendente, la Audiencia recuerda que la parte dispositiva del auto debe interpretarse junto con su fundamentación jurídica, y en ésta si se aborda en profundidad la cuestión de la ilicitud del traslado.

\section{La ilicitud del traslado de los menores}

15. Entrando en las cuestiones de fondo, la primera cuestión a analizar es la discusión en torno a la ilicitud del traslado de los menores de Reino Unido a España.

16. Para abordar esta cuestión, debemos comenzar recordando la normativa específica relativa a la sustracción internacional de menores aplicable al caso concreto. Al trasladarse a los menores de su residencia habitual en un Estado miembro de la UE (Reino Unido) a otro Estado miembro de la UE (España), es de aplicación el Reglamento n. ${ }^{\circ}$ 2201/2003 del Consejo, de 27 de noviembre de 2003, relativo a la competencia, el reconocimiento y la ejecución de resoluciones judiciales en materia matrimonial y de responsabilidad parental ${ }^{7}$ (en adelante Reglamento Bruselas II bis). A su vez, este Reglamento remite expresamente el Convenio de La Haya de 25 de octubre de 1980 sobre aspectos civiles del secuestro in-

\footnotetext{
${ }^{5}$ Textualmente, el artículo 778 quinquies apartado noveno, señala que "Celebrada la vista y, en su caso, practicadas las pruebas pertinentes, dentro de los tres días siguientes a su finalización, el Juez dictará sentencia en la que se pronunciará únicamente sobre si el traslado o la retención son ilicitos y acordará si procede o no la restitución del menor a la persona, ... La resolución que acuerde la restitución del menor o su retorno establecerá detalladamente la forma ý el plazo de ejecución, pudiendo adoptar las medidas necesarias para evitar un nuevo traslado o retención ilicito del menor tras la notificación de la sentencia".

${ }^{6} \mathrm{Si}$ bien es cierto que, para el recurso de apelación, el citado artículo 778 quinquies, en su apartado undécimo, utiliza el término genérico de resolución: "Contra la resolución que se dicte sólo cabrá recurso de apelación con efectos suspensivos... e) La resolución deberá ser dictada dentro de los tres días siguientes a la terminación de la vista...”. Aún así, el apartado 13 del artículo 778 quinquies vuelve a hacer referencia al término de sentencia en los relativo a la ejecución: "En la ejecución de la sentencia en la que se acuerde la restitución del menor...".

${ }^{7}$ DO L 338 de 23 de diciembre de 2003, cde DO L 82, de 22 de marzo de 2013.
} 
ternacional de menores ${ }^{8}$ (en adelante Convenio de La Haya de 1980), pero a su vez introduciendo ciertas modificaciones procesales al procedimiento de retorno del menor recogido en el texto convencional ${ }^{9}$. Por tanto, en este supuesto de hecho se deben aplicar conjuntamente ambos instrumentos internacionales.

17. El punto de partida de todo procedimiento de sustracción internacional de menores es la existencia de un traslado o retención ilícita, pues es el presupuesto para que se active el mecanismo de retorno del menor. Es por esta razón que tanto el Convenio de La Haya de 1980 (artículo 3) como el Reglamento Bruselas II bis (artículo 2.11) recogen una definición, en términos muy similares, de la noción de traslado o retención ilícita. Así, se entiende que habrá traslado o retención ilícita cuando: a) Se haya producido con infracción de un derecho de custodia atribuido, separada o conjuntamente, a una persona, a una institución, o a cualquier otro organismo, con arreglo al Derecho vigente en el Estado en que el menor tenía su residencia habitual inmediatamente antes de su traslado o retención. El derecho de custodia deberá resultar de una atribución de pleno derecho, de una decisión judicial o administrativa, o de un acuerdo vigente según el Derecho de dicho Estado. b) Este derecho se ejercía de forma efectiva, separada o conjuntamente, en el momento del traslado o de la retención, o se habría ejercido de no haberse producido dicho traslado o retención.

18. En el caso enjuiciado la Audiencia Provincial de Mallorca no tiene duda de que el traslado de los menores de Reino Unido a España ha sido ilícito, pues ha sido un acto unilateral del padre de los niños. Teniendo en cuenta, principalmente, que en virtud de la legislación de Reino Unido la facultad para decidir el lugar de la residencia habitual y el traslado de los menores corresponde conjuntamente a ambos progenitores. Por tanto, pese a que no se especifica como están establecidos los derechos de custodia y visita de los menores, es claro que para trasladar a los menores se requería el consentimiento, en este caso, materno.

19. Se intuye, por tanto, que el consentimiento del progenitor no sustractor es otro de los elementos clave para determinar la ilicitud del traslado. Efectivamente, en el caso en cuestión el padre sustractor alega que la madre ha consentido dicho traslado. Sin embargo, debido a la conexión del consentimiento de la madre con una de las excepciones al retorno esta cuestión es examinada íntegramente en el apartado siguiente.

\section{El consentimiento de la madre como excepción al retorno.}

20. Como se ha anticipado en el apartado anterior, en la discusión en torno a la licitud o ilicitud del traslado, la parte recurrida alega que la madre consintió el traslado de los menores de Reino Unido a España.

21. El Convenio de La Haya de 1980 se construye sobre el principio del interés superior del menor, identificado con el retorno inmediato a su lugar de residencia habitual inmediatamente anterior al traslado o retención ilícito ${ }^{10}$. En palabras de la Audiencia Provincial, el Convenio tiene por objetivo

\footnotetext{
${ }^{8}$ BOE n. $^{\circ} 202$, de 24 de agosto de 1987, corr. errores BOE n. ${ }^{\circ} 155$, de 30 de junio de 1989, y BOE n. ${ }^{\circ} 21$, de 24 de enero de 1996.

${ }^{9}$ La relación entre ambos instrumentos ha sido ampliamente tratada por la doctrina, entre otros: N. LOWE, M. EvERAL QC Y M. Nicholls: The New Brussels II Regulation. A supplement to International Movement of Children, Family Law, Bristol, 2005; U. Magnus y P. Mankowski: Brussels IIbis Regulation, Sellier European Law Publishers, Munich, 2012; K. Trimmings: Child Abduction within the European Union, Hart Publishing, Oxford and Portland, 2013; I. ReIG FaBADO: "Incidencia del Reglamento 2201/2003 en materia de sustracción internacional de menores: interacción con el Convenio de La Haya de 1980", en P. LLÓRIA GARCÍA (dir.): Secuestro de menores en el ámbito familiar: un estudio interdisciplinar, Iustel, Madrid, 2008, pp.219-242; M. GuZMÁN PecEs: "Problemática en la coordinación de los instrumentos normativos aplicable a la sustracción de menores y en particular a la interpretación de la residencia habitual", Anuario Español de Derecho Internacional Privado, t. XIV-XV, 2014-2015, pp. 489522; P. MCeleavY: "The new Child Abduction Regime in the European Union: Symbolic Relationship or Forced Partnership?", Journal of Private International Law, vol. 1, April 2005, pp. 5-34; I. ReIG FABADO: "El traslado ilícito de menores en la Unión Europea: retorno vs. violencia familiar o doméstica”, Cuadernos de Derecho Transnacional, vol. 10, n 1, marzo 2018, pp. 610-619.

${ }^{10}$ De conformidad con la finalidad del retorno del menor en el menor plazo posible, el párrafo primero del artículo 12 prevé que, en caso de un traslado o retención ilícito, la autoridad competente del Estado contratante en el que se encuentra el menor
} 
restablecer la situación tal y como se hallaba antes de producirse una acción ilícita que vulnera el derecho de custodia. Sin perjuicio de la prioridad hacia el retorno del menor, el texto convencional ofrece un cierto equilibrio entre el retorno y las situaciones concretas en las que el menor puede estar en riesgo $-\mathrm{y}$ ello justificar su no retorno- ${ }^{11}$.

De este sistema se extrae claramente el carácter excepcional de las situaciones por las que se permite denegar el retorno de un menor tras un traslado ilícito. La Audiencia Provincial incide en este punto, insistiendo en que no es posible presumir la concurrencia de tales excepciones, sino al contrario, es necesario demostrar su concurrencia. Es más, una de las modificaciones procesales que introduce el Reglamento Bruselas II bis respecto al sistema diseñado en el Reglamento es la limitación de la excepción al retorno previstas en el texto convencional. Así, el artículo 11.4 del Reglamento establece que los órganos jurisdiccionales no podrán denegar el retorno de un menor con base al artículo $13 \mathrm{~b}$ del texto convencional en caso de que se demuestre que se han adoptado las medidas de protección pertinentes en el Estado de residencia habitual del menor con carácter anterior al traslado o retención ilícito.

22. En este marco, una de las excepciones al retorno del menor es precisamente el consentimiento del progenitor no sustractor. Concretamente, el artículo 13 a) del Convenio establece que las autoridades nacionales deberán denegar el retorno en caso de que la persona, institución u organismo que se hubiera hecho cargo de la persona del menor "había consentido o posteriormente aceptado el traslado o retención". Del artículo 13 a) se extrae, por tanto, que el consentimiento del progenitor no sustractor se puede obtener en dos momentos temporales. Con carácter anterior al traslado o retención de los menores, de tal manera que ya no concurriría la nota esencial de la ilicitud del traslado. O bien posteriormente, una vez los menores han sido trasladados o retenidos ilícitamente, el progenitor no sustractor puede convalidar dicha situación dando su consentimiento ex post.

23. La parte apelada afirma que los días 23 y 24 de septiembre de 2017 la madre acudió a ver a sus hijos a Mallorca. Además, pudo comprobar que se encontraban escolarizados, siendo usuaria de la aplicación del centro escolar y habiendo mostrado su acuerdo en la matriculación de los menores al centro en cuestión. Frente a las alegaciones del padre sustractor, el Ministerio Fiscal y la parte recurrente entienden que ni la carta supuestamente manuscrita por la madre, ni sus hipotéticos deseos de ir a vivir a Mallorca con sus hijos suponen una autorización expresa de la madre para trasladar a los niños a Mallorca.

24. La Audiencia Provincial acoge esta última postura, confirmando que no se ha otorgado ningún consentimiento o autorización expresa por parte de la madre, ni con anterioridad al traslado ni posteriormente. De esta manera, del auto objeto de comentario se extrae que los elementos fácticos siguientes no son suficientes para constituir un consentimiento de la madre al traslado de los menores a Mallorca, y por tanto, para enervar la ilicitud del traslado de los menores: el hecho de que los menores visitaran con carácter habitual a sus abuelos paternos en Mallorca; que los progenitores se han visto envueltos en una crisis de pareja y no hay un acuerdo en relación al traslado de los menores; tampoco las visitas de la madre a casa de sus suegros en septiembre de 2017; ni siquiera las solicitudes de escolarización de los menores suscritas por la madre, puesto que la Audiencia añade que éstas son obligadas y que podrían estar motivadas en el deseo de la madre de que los niños no perdieran el curso escolar o en arreglar la situación del matrimonio; tampoco son trascendentes el deseo de la madre de mudarse a Mallorca, o los contenidos de whats app - que no se reproducen en el auto analizado -. Todo ello se refuerza precisamente con la denuncia presentada por la madre del traslado de los menores a Mallorca, aspecto también remarcado en la S.A.P de Alicante (Sección Sexta) nº 208/2017, de 11 de julio y nº 195/2016, de 26 de julio.

25. En definitiva, el auto de la Audiencia Provincial, al contrario que el Juzgado de Primera Instancia, resuelve acertadamente al no inferir el consentimiento de la madre al traslado de los menores de los elementos fácticos enumerados. En este mismo sentido, la Sentencia de la Audiencia Provincial de las

deberá ordenar su restitución inmediata, siempre que haya transcurrido menos de un año desde que se produjo tal traslado o retención ilícita.

${ }^{11}$ Las causas de denegación de retorno están previstas en los artículos 12, 13 y 20 del Convenio de La Haya de 1980. 
Palmas de Gran Canaria, sección $3^{\mathrm{a}}$, de 21 de junio de 2017, concluye que la situación pasiva de tolerancia, motivada por la buena relación entre la madre del menor con su expareja y con la madre de éste, no debe entenderse como una renuncia automática al derecho de guarda ${ }^{12}$. Por el contrario, el consentimiento debe ser inequívocamente manifestado y ser probado en el procedimiento por quien lo alega.

\section{La enfermedad psiquiátrica de la madre como excepción al retorno por grave riesgo de los menores}

26. Quizá el aspecto que más interés suscita de la resolución analizada es la alegación de la enfermedad psiquiátrica de la madre como motivo de excepción del retorno de los menores a Reino Unido.

27. Concretamente, el artículo 13 b del Convenio de La Haya de 1980 permite excepcionar el retorno del menor en caso de que la restitución suponga para el menor un grave riesgo, exponiéndole a un peligro físico o psíquico, o le ponga de cualquier otra manera en una situación intolerable. De este precepto se deduce que en el asunto en cuestión debería probarse la existencia de un grave riesgo para los menores en caso de que se ordene el retorno de los mismos, debido a la enfermedad psiquiátrica de la madre.

Es evidente que dentro de esta previsión genérica tienen cabida múltiples situaciones concretas, en las que las autoridades nacionales son las encargadas de interpretar caso por caso la concurrencia o no de una situación de peligro en caso de retorno de los menores. Precisamente por este motivo, en la práctica, esta excepción suele ser habitualmente empleada por las autoridades nacionales para excepcionar el retorno. Tan habitual ha sido la aplicación de la excepción del artículo 13 b del Convenio que se ha llegado a hablar de un abuso de su utilización en la práctica ${ }^{13}$.

28. Confirmando la tendencia en la práctica a ampararse en esta excepción, la resolución de primera instancia entiende que debe aplicarse la excepción del artículo 13 b del Convenio de La Haya de 1980. En este sentido, acoge la tesis del padre de los menores, quien incide en los numerosos ingresos psiquiátricos que ha padecido la madre, llegando a afirmar que la madre no puede hacerse cargo de los menores debido a su enfermedad mental, puesto que colocaría a los menores en un grave riesgo. Por el contrario, tanto el Ministerio Fiscal como la madre entienden que la prueba practicada en vista desvela que la madre, pese a padecer una enfermedad psíquica, se encuentra debidamente medicada y en modo alguno cabe afirmar que dicha enfermedad se encuentra fuera de control.

29. Frente a estas posturas, la Audiencia Provincial entiende que el traslado de los menores no puede justificarse en la hospitalización de la madre en aquel momento, pues no queda acreditado que dicha hospitalización respondiera a un agravamiento de la enfermedad, ni a la realización por la madre de hechos o por haber protagonizado comportamientos más graves y preocupantes que en otras ocasiones. Por tanto, la Audiencia no encuentra una razón concreta para explicar porqué el padre realiza el traslado de los menores en esa fecha y no en cualquier momento anterior, en que ya conocía la enfermedad. Y en este sentido, no consta que el ingreso de la madre respondiera a conductas más graves que hayan colocado a los niños en una situación de peligro físico o psíquico.

${ }^{12}$ Véase JJ. CAstelló PAStor: "Excepciones legales al retorno del menor en los supuestos de sustracción internacional”, Cuadernos de Derecho Transnacional, vol. 10, n. ${ }^{\circ}$ 1, marzo 2018, pp. 561-567.

${ }^{13}$ Los problemas de aplicación práctica de la excepción de retorno del artículo 13 b) del Convenio de La Haya de 1980 han sido puestos de relieve por numerosa doctrina. En este sentido, véase M. GuZMÁn Peces: «Problemática en la coordinación de los instrumentos normativos aplicable a la sustracción de menores y en particular a la interpretación de la residencia habitual», Anuario Español de Derecho Internacional Privado, t. XIV-XV, 2014-2015, p. 503; J. ForCADA MIRANDA: «El nuevo proceso español de restitución o retorno de menores en los supuestos de sustracción internacional: La decidida apuesta por la celeridad y la novedosa Circular de la Fiscalía 6/2015 (Parte I)», Bitácora Millennium DIPr., n. ${ }^{\circ} 3,2016$, p. 32. Versión on line disponible en www.milleniumdipr.com, último acceso el 12 de enero de 2019. Sin embargo, esta afirmación no es unánime en la doctrina, ya que hay autores que afirman que el problema no es tanto el propio artículo 13 b) sino la deficiente efectividad de las medidas de protección, en esta línea K. Trimmings: Child Abduction within the European Union, Hart Publishing, Oxford and Portland, 2013. 
30. Para evaluar el estado de la madre en relación con la mencionada enfermedad psiquiátrica que padece, la Audiencia Provincial basa su argumentación, en el informe médico-forense de 11 de enero de 2018, sobre valoración de la afectación psico-física de la madre y su repercusión en los elementos integrantes de capacidad, así como su estado mental actual, deteniéndose considerablemente en la descripción de los elementos fácticos contenidos en el mismo. La valoración global del médico forense es que la madre posee buen estado físico y buen ánimo, sin impresionar patología psicofísica de ninguna clase ${ }^{14}$. A la vista de ello, la Audiencia Provincial concluye que, ni el informe mencionado ni los demás dictámenes médicos incorporados a la causa, permiten afirmar que la permanencia de los menores con la madre hubiese causado en ellos un perjuicio o daño físico o psíquico o les pudiera colocar en una situación de grave riesgo. Por extensión, tampoco hay elementos de prueba suficientes para predecir que, en caso de que los menores vuelvan con ella, futuras recaídas de ésta puedan colocarles en una situación de peligro.

31. Ahora bien, como bien argumenta la Audiencia Provincial, ésta debe limitarse a conocer sobre la ilicitud del traslado de los menores y sobre el retorno o no de los mismos, comprobando la concurrencia o no de elementos fácticos que permitan aplicar una de las excepciones al retorno contenidas en los artículos 12, 13 y 20 del Convenio. Efectivamente, la propia lógica del Convenio impide a la autoridad nacional conocer sobre el fondo de la cuestión, esto es, sobre los derechos de custodia y visita, puesto que dicha cuestión deberá resolverse en el Estado de residencia habitual de los menores con carácter previo al traslado o retención ilícito ${ }^{15}$. Por su parte, el 10 del Reglamento Bruselas II bis contempla una norma específica para los supuestos de sustracción internacional de menores, con el objetivo de conservar la competencia para conocer sobre el fondo de la cuestión en favor de los órganos jurisdiccionales del Estado de residencia habitual del menor con carácter previo al traslado o retención ilícito, en este caso Reino Unido. Con ello, el artículo 10 refuerza la competencia general del artículo 8 para supuestos de responsabilidad parental - Juez de residencia habitual del menor -, impidiendo que se desvirtúe la competencia judicial internacional en la materia (fondo del asunto) a través de un traslado o retención ilícito.

32. Por ello, una vez restaurada la acción ilícita y retornado los menores a Reino Unido, nada impide al progenitor iniciar las acciones correspondientes para atribuir la custodia de los menores al progenitor que resulte más conveniente. Teniendo en cuenta que se presume que serán los órganos jurisdiccionales de Estado miembro de residencia habitual del menor los que poseerán mejores elementos de juicio para valorar la mayor o menor conveniencia de que los menores estén con uno u otro progenitor. Por tanto, una vez evaluado y descartado que el retorno de los menores a Reino Unido constituya un riesgo de peligro físico o psíquico de los menores, los órganos jurisdiccionales de Reino Unido serán los que deban valorar si la madre es capaz o no de cuidar a los menores debido a su enfermedad psiquiátrica.

\section{Valoración final}

33. El auto analizado desvela un supuesto clásico de sustracción internacional de menores, en el que la Audiencia Provincial interpreta y aplica correctamente la normativa en la materia, con especial referencia al Convenio de La Haya de 1980. Concretamente, es muy acertada su argumentación acerca de la ilicitud del traslado; así como del carácter excepcional de las excepciones al retorno y la necesidad

\footnotetext{
${ }^{14}$ Textualmente, en el auto se recoge que "Además, se afirma que la recurrente "es consciente de su enfermedad y de su situación vital, prestando cuidado suficiente a su estado de salud y que cumple con las prescripciones médicas necesarias para su bienestar, reconociendo que los estresores, que trata de evitar, le pueden provocar virajes y mostrando conocimiento de las consecuencias de sus decisiones, no realizando proyectos ilógicos a corto o a largo plazo y sin que aparezcan tampoco ideas extrañas sobre qué hacer en un futuro con alguna nueva relación o con sus hijos, de manera que su capacidad psicofísica actual para garantizar el bienestar socio-personal se encuentra indemne, no precisando de asistencia y complemento de su capacidad psicofisica para la supervisión de sus labores".

${ }^{15}$ El artículo 16 del Convenio contiene una norma de competencia judicial internacional negativa por la cual, los Tribunales del Estado miembro al que ha sido trasladado o retenido ilícitamente el menor, no podrán decidir sobre el fondo de los derechos de custodia (a no ser que se decida el no retorno del menor en virtud del Convenio o haya transcurrido un tiempo razonable).
} 
de interpretarlas restrictivamente y demostrando todos sus extremos para aplicarlas. Asimismo, la Audiencia es plenamente consciente de que debe limitarse a conocer sobre el retorno o no de los menores, sin entrar en el fondo del asunto, cuestión cuya competencia la tienen atribuida los órganos jurisdiccionales de Reino Unido. En este sentido, cabe acoger positivamente el cambio de criterio -retorno de los menores a Reino Unido- frente a la resolución de primera instancia.

34. Sin embargo, hay dos puntos en los que la Audiencia podría haber incidido en mayor profundidad. En primer lugar, tal y como alega el Ministerio Fiscal, concurre un defecto formal en la resolución de primera instancia, ya que según el artículo 778 quinquies, apartado 9, el Juez dictará sentencia ordenando o no la restitución de los menores al lugar de su residencia habitual. En segundo lugar, la Audiencia Provincial no hace prácticamente mención al Reglamento Bruselas II bis, a pesar de haberse producido la sustracción de los menores entre dos Estados miembros de la UE. En este sentido, a pesar de que es sabido que el propio Reglamento remite al Convenio de La Haya de 1980, con las modificaciones que estable el Reglamento, la Audiencia podría haber hecho referencia expresa al Reglamento, mientras que solo lo hace tangencialmente al mencionar el auto de primera instancia. 